\title{
Factors Affecting Software Cost Estimation in Developing Countries
}

\author{
Ali Javed \\ Department of Software Engineering, University of Engineering and Technology, Taxila, Pakistan \\ E-mail: ali.javed@uettaxila.edu.pk \\ Mirza Ahsan Ullah \\ Department of Software Engineering, University of Engineering and Technology, Taxila, Pakistan \\ E-mail: mirza_ahsan48@yahoo.com \\ Aziz-ur-Rehman \\ Department of Software Engineering, University of Engineering and Technology, Taxila, Pakistan \\ E-mail: comsian_17@yahoo.com
}

\begin{abstract}
Cost is the main driving factor for all projects. When it is done correctly, it helps in the successful completion of the project. In this research we have discussed various factors that affect the estimation procedure. These include team structure, team culture, managerial style, project type (Core application or integrated application), client's working environment. Accurate estimation is far difficult in developing countries where most of the organizations follow local standards. These inaccurate estimations lead to late delivery, less profit or in worst case complete failure.

Software requirement gathering, development, maintenance, quality assurance and cost of poor quality are major groups responsible for overall cost in software production process. The exact proportion among them varies significantly in consecutive software releases, which is caused by many factors. The ever increasing need for the reliability of the software systems, especially mission critical applications in the public safety domain, raises the bar for the accuracy of prediction and estimation techniques. The accuracy of estimations in many areas brings about more concerns regarding techniques already used in the software industry. Widely deployed techniques, such as Wideband Delphi method, stress the engineering and technical aspects of the process of how estimates are prepared.
\end{abstract}

Index Terms - Wideband Delphi, Cost Estimation, Work break Structure (WBS)

\section{Introduction}

Estimation of cost and time required to complete a task, project or to develop a new system depends upon the scope and complication of that particular system. Estimation is an art which is different for every expert means how he/she visualizes the problem and how they approach towards solving that particular problem. For instance same problem can be solved by a person in few minutes while the other takes few hours to solve the problem. Estimation at initial level is very much prejudiced because estimator doesn't know the practicalities and hurdles which one will have to face while accomplishing a task. Estimation performed by different people will be different as the reasons discussed above. The focus should be on accurate estimation and this can be achieved by performing estimation from different people and minimizing the variance in those estimates. [2]

Estimating a project is far difficult for a person especially for a person who is not aware of practical complexities or has a little or no knowledge about the field of the project. So the estimator is supposed to be an experienced person of the relevant field so that he will be able to estimate the project cost and schedule more sensibly. Wrong estimates lead to extension in time or budget of the project and sometimes to the failure of the project.

Accurate estimates at early stages are very difficult, due to the incomplete or a very little information about the future of the project, but are necessary in some cases, i.e. for bidding a project or getting a contract [2]. These estimations are far difficult in developing countries, where most of the companies follow self-built standards and need a software solution to fit in that particular scenario. This demands a solution which in most of the cases hardly predicts what is it? , before it evolves finally. For example a client demands that he needs a Point of Sales (POS) to be used in garment store. but when we actually get the info we come to know that it is POS but actually have some additional features which are not the part of the standard POS. in such cases estimation is difficult . 
This paper is organized as follows: Section 2 includes problem statement. Section 3 then describes the project types and major factors those have high influence over cost estimation. Section 4 provides the literature review and work done related to this in the past. Finally section 5 describes the results of survey and the analysis.

\section{Statement of Problem}

Cost estimation is difficult part of project even in developed countries which are using specialized tools and techniques to estimate it, but it's too difficult in developing countries where beside these difficulties many problems arise due to local estimation style, technology or methodology used and the client's unpredictable behavior. In this paper we are going to reveal the main problems the developing countries are facing, their root causes and their proposed solutions.

\section{Factors Involved in Failure to Meet Estimated Cost}

\subsection{Project type}

By the application type the software projects can be divided into two major types.

i. Core projects

ii. Integrated projects

The core projects are easy to estimate as they don't depend on any other software and we are free to make its design of our own convince. But in integrated type projects we have constrains to be followed. We have to consider the system, with which we have to integrate our application. We also suffer from many unseen problems while deploying the project. In this perspective integrate projects are hard to estimate as are attached with unpredictable factors.

\subsection{Authoritative style}

According to our survey, the project manager style also plays a vital role in the success or failure of the project. In developing countries where the requirement might be changed at any stage, even when a treaty is signed (when client is unable to describe its requirements clearly or forget to tell) the participative style proved better rate of success. Because the team leader knows the ground realities and if his/her opinion is considered, estimation will be more accurate.

\subsection{Team members expertise}

During the estimation process the most important factor is neglected, which is how much expert resources we actually need to accomplish a project within given time, resources and schedule. This is the more dominating factor affecting the estimation process badly. We actually don't consider the expertise in team formation that we actually need in most cases.

\subsection{Not consider actual routines}

In routine practice when the estimation is made the project manager and team is considered as the dedicated one. But in many situations it's hard to do if the project is not making a reasonable profit in a reasonable time. Often the team members are re-allocated according to stress in our ongoing projects. This also effects the pace and cost of the project.

\subsection{Project strategy}

According to our careful study, in developing countries even if requirement gathering process is initiated and other similar techniques to guess the original requirements (e.g., prototyping ) even then clients miss about $30 \%$ of their general requirements and about $7 \%$ of their core requirements.

\section{Literature Review}

The results show that the agile methodologies are having more success rate than those of standard sequential methodologies. Agile methodologies can be applied to small and collocated teams as these methodologies emphasis on discussions and face to face conversations instead of writing comprehensive documents. Agile methods promote communication over documentation. [3]

Agile methodologies meetings are different as compared to those of cultural meetings as it focus on extracting meaningful information and making decision rather than delaying the decisions for next meeting. [4]

Agile policy is to communicate often to share ideas and by involving customer in to communication better understanding of user needs so that later on customer cannot make issues. [5]

Modern agile methodologies focus on user satisfaction at early stage of the project. This can be accomplished by delivering a module or sub module of a system to be developed. As the delivery of a working application is the best way to show the progress of the project and to gain the satisfaction of the user. [6]

The study shows that about $95 \%$ projects requirements continuously evolve as it progresses towards its completion. To counter this, agile methods takes an iterative approach by doing meetings with user after specific time or whenever some new dependency among the modules are introduced. At initial stage the user is asked to write user stories to elaborate the functionalities which are expected from the system to be performed. [7]

User requirements are gathered in the form of user stories and these are estimated by the developers. Then further iterations are planned by involving the whole team including developers, team leads and managers. The priorities are formulated with the help of team members and users. This approach requires co-located 
teams because extensive no of result oriented meetings cannot be performed without this. Otherwise the meetings are less meaningful. [8]

Wide band Delphi technique is used to estimate the user stories by involving developer and customer hence better understanding of customer requirements and minimizing the chance of error in getting requirements. [3]

WBDT is useful in a sense that it really enhances the team work by involving the team members in the process of estimation including the developers. Team members help each other to minimize the mistakes thus increasing the trust among team members. The managers usually take the role of Moderator whose responsibility is to select the team for estimation and provide the documentation (WBS, user stories) necessary to perform the meaningful estimation. These documents include major deliverables to the customer as well as lower and upper bounds of the project and user stories are provided to all the selected team members for estimation by individually evaluating the task. These individual estimates are then discussed, evaluated and refined further in a meeting under the supervision of the moderator usually a Manager. Meeting time can vary according to the project type and complexity. Meeting is usually carried out in iterative approach by reevaluating and estimating the task unless the variation in estimates performed by all team members can be minimized up to the acceptable limit.
The main idea here in WBDT is to get an estimate that is agreed by all the team members and consensus is developed. WBDT supports and work well under the Participative managerial style. WBDT estimates are more realistic and can be changed as you will need to accommodate the new requirements of the user. The probability of the changes will be very low because by involving customer in the estimation meeting the chance of misunderstanding the user requirements is no more an issue.

\section{Results and Analysis}

Survey conducted on the basis of different projects which based on
i. Project type
ii. Managerial Behavior
iii. Estimated Time
iv. Estimated cost
v. Actual Completion Time
vi. Actual cost

Data which gathered during survey conducted is shown under in the form of tables. Data is divided in to two tables by distinguishing the projects by their types.

Table 1: Data of core systems

\begin{tabular}{|c|c|c|c|c|c|c|c|}
\hline & $\begin{array}{c}\text { Project } \\
\text { Type }\end{array}$ & $\begin{array}{c}\text { Estimation } \\
\text { Style }\end{array}$ & $\begin{array}{c}\text { Client } \\
\text { Int. } \\
\text { Standard }\end{array}$ & $\begin{array}{c}\text { Estimated } \\
\text { time } \\
\text { (months) }\end{array}$ & $\begin{array}{c}\text { Estimated } \\
\text { cost } \\
(U S \$)\end{array}$ & $\begin{array}{c}\text { Actual } \\
\text { Completion } \\
\text { time(months) }\end{array}$ & $\begin{array}{c}\text { Actual } \\
\text { cost } \\
(U S S)\end{array}$ \\
\hline Project Cl & Core & Participative. & No & 10 & 20,500 & 10 & 22,700 \\
\hline Project C2 & Core & Participative. & Yes & 18 & 28,000 & 19 & 29,200 \\
\hline Project C3 & Core & Participative. & No & 13 & 27,500 & 13.5 & 28,200 \\
\hline Project C4 & Core & Participative. & No & 5 & 11,000 & 5 & 11,000 \\
\hline Project C5 & Core & Participative. & Yes & 6 & 13,500 & 6 & 13,500 \\
\hline Project C6 & Core & Authoritative & Yes & 8 & 14,700 & 8 & 14,700 \\
\hline Project C7 & Core & Authoritative & No & 9 & 17,000 & 9.25 & 17,400 \\
\hline Project C8 & Core & Authoritative & Yes & 8 & 35,000 & 8.5 & 36,000 \\
\hline
\end{tabular}

Table 2: Data of Integrated systems

\begin{tabular}{|c|c|c|c|c|c|c|c|}
\hline & $\begin{array}{c}\text { Project } \\
\text { Type }\end{array}$ & $\begin{array}{c}\text { Estimation } \\
\text { Style }\end{array}$ & $\begin{array}{c}\text { Client } \\
\text { Int. } \\
\text { Standard }\end{array}$ & $\begin{array}{c}\text { Estimated } \\
\text { time } \\
\text { (months) }\end{array}$ & $\begin{array}{c}\text { Estimated } \\
\text { cost } \\
(U S S)\end{array}$ & $\begin{array}{c}\text { Actual } \\
\text { Completion } \\
\text { time(months) }\end{array}$ & $\begin{array}{c}\text { Actual } \\
\text { cost } \\
(U S S)\end{array}$ \\
\hline Project Il & Integrated & Participative. & No & 4 & 5,500 & 4 & 5,800 \\
\hline Project I2 & Integrated & Participative. & Yes & 3 & 6,000 & 3.25 & 6,450 \\
\hline Project I3 & Integrated & Participative. & Yes & 4 & 6,500 & 4 & 6,500 \\
\hline Project I4 & Integrated & Participative. & No & 5 & 7,500 & 6 & 9,000 \\
\hline Project I5 & Integrated & Authoritative. & Yes & 3 & 5,000 & 3 & 5,000 \\
\hline Project I6 & Integrated & Authoritative. & No & 7 & 11,000 & 7.5 & 12,000 \\
\hline Project I7 & Integrated & Authoritative. & No & 2.5 & 4,000 & 3 & 4,400 \\
\hline Project IS & Integrated & Authoritative. & Yes & 5 & 8,500 & 6 & 9,500 \\
\hline
\end{tabular}




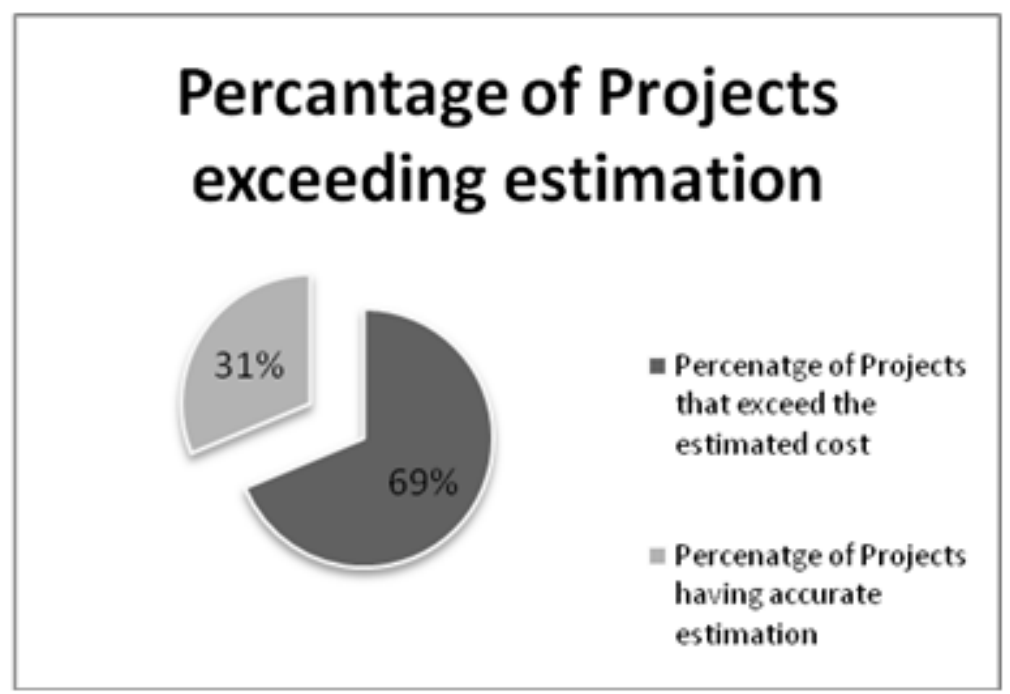

Fig. 1: Percentage of projects exceeding estimated cost

Above diagram shows the results of our survey which was conducted on different IT projects. According to survey $69 \%$ projects exceeds the cost which was estimated at the start of the project. There are various factors which results in failure of these estimations. Result shows that out of 100 only 31 projects have successful estimation in both cost and timeline to complete the project.

\subsection{Core Vs. Integrated}

The preceding chart shows the effect of application type on the project estimation. We have taken two major application types as discussed earlier these are core and integrated applications. Above chart shows that on average core application increase $2.75 \%$ of their estimated cost. Integrated applications on average increases $8 \%$ of their estimated cost. As in integrated systems there are many issues regarding integration with the existing system which is already deployed in the company. Being a developer you need the comprehensive study of the existing system.

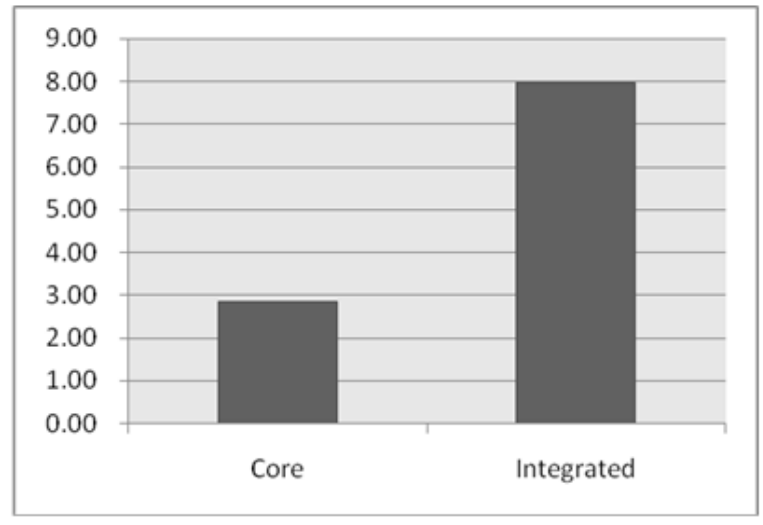

Fig. 2: Increase in cost in core and integrated projects estimation on average

\subsection{Participative Vs. Authoritative}

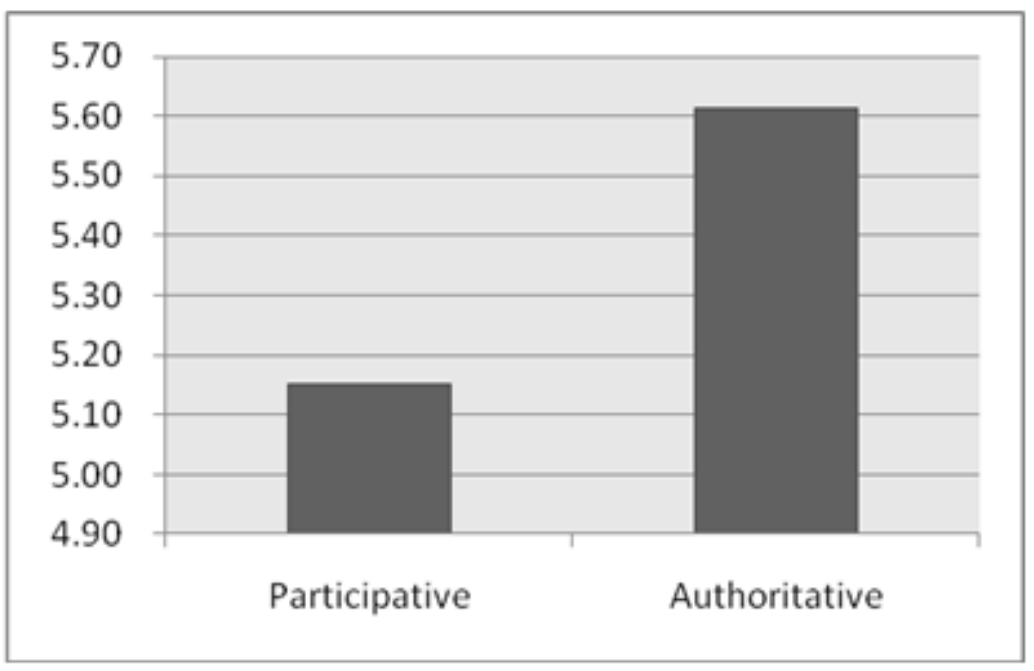

Fig. 3: Increase in cost in participative and Authoritative type of estimation on average 
Above chart shows the analysis of managerial style. Result shows that by following participative management style in every aspect like estimation, decision making we can make accurate estimation. Participative style supports Wideband Delphi technique[1] which includes all team members including customer hence enhances team work and chance of accurate estimation. Authoritative style is more in favor of dictation rather than team environment. Result shows that it is not a good practice.

\subsection{Non-standard Vs. Standard Organizations}

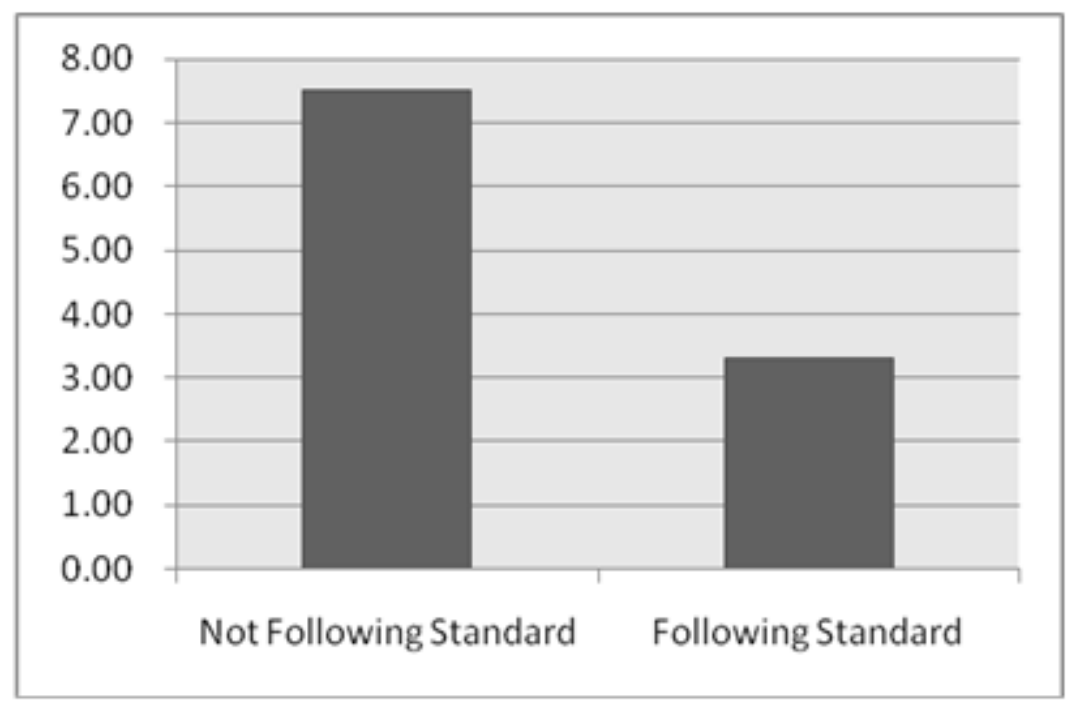

Fig. 4: Increase in cost in organization following and not following standards on average

Another important factor is analyzed which is company standards for which we are developing an application. Result in above chart shows that if a company does not follow the international standards then their application development is difficult because things are not managed well and this increases the work of developers and estimators. The company having no standards very often increases the estimated cost. The company having international standards can easily meet the estimated cost and the projects are more successful for those companies.

\subsection{Composite Analysis}

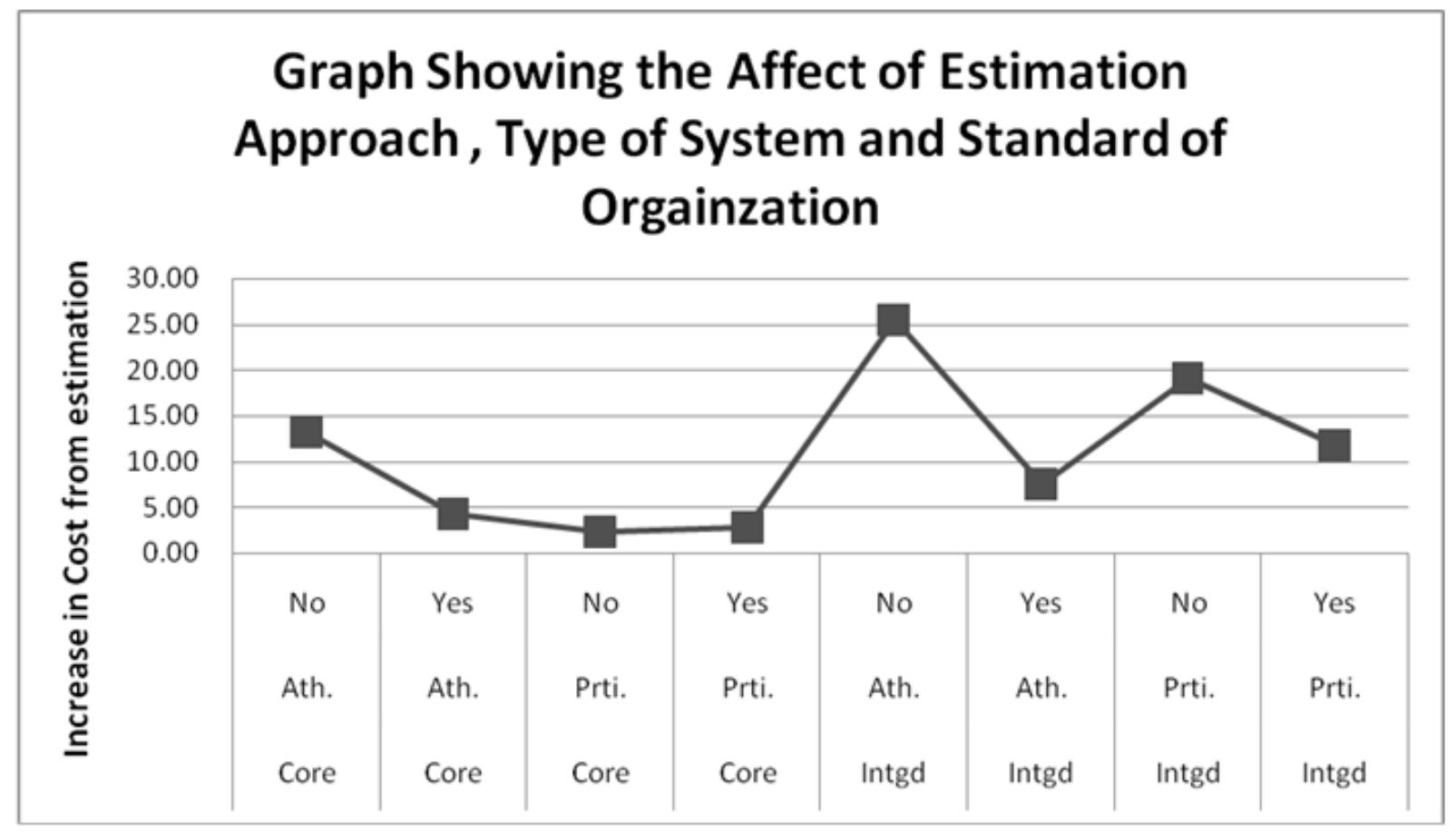

Fig. 5: Composite analysis of all the features of core and integrated projects 
The above graph shows the composite analysis of the three factors. Project type, Managerial style, company standards .There is high increase of $25 \%$ in estimation when company was having no standard and project type was also integrated and the management was authoritative. When the same thing was applied when company having international standard then the value is decreased to 8 . That shows how important is that company should have some standards. The graph also shows that core systems are having fewer variations than integrated systems in relatively same circumstances. The left half of the graph is performing well as compared to right half due to the domination of core systems at the left half.

\section{Conclusion and Future Work}

For all the above facts and figure, we concluded that applying wideband Delphi technique to carry out estimation will be helpful as it involves much active participation of the stake holders, also it the organization is following some international standards then it will be much helpful and accurate. The estimation of core projects is much easier as compare to the integrated projects. Also projects of organization following the standards are easy to estimate. In future much worked can be done in developing a model to deal with the estimation of projects of companies following no pact international standards. Also a development technique can be developed to deal with the issues mention in paper to improve the efficiency of the software projects.

\section{References}

[1] Marek Grzegorz Stochel ,Motorola Solutions Kraków, Poland, 35th IEEE Annual Computer Software and Applications Conference, 2011.

[2] Stellman, J. Greene. "Applied Software Project Management”,O'Reilly, 2005.

[3] Giovanni Aiello, Marco Alessi, Massimo Cossentino, Alfonso Urso, Giuseppe Vella, "RealTime Distributed Wideband-Delphi for user stories estimation “

[4] Green, Kesten C., Armstrong, J. Scott and Graefe, Andreas, "Methods to Elicit Forecasts from Groups:Delphi and Prediction Markets Compared “, September 22, 2007

[5] Thomas Chau, Frank Maurer: "Knowledge Sharing in Agile Software Teams. Logic versus Approximation”,,(2004) 173-183.

[6] "Kent Beck: Extreme programming explained", Addison-Wesley (2000).

[7] Paul Prior, Frank Keenan: "Requirements Management in a Distributed Agile Environment",
Transaction on engineering, computing and technology 4, (2005).

[8] Mike Cohn: "User Stories Applied - For Agile Software Development", Addison Wesley (2004).

\section{Authors' Profiles}

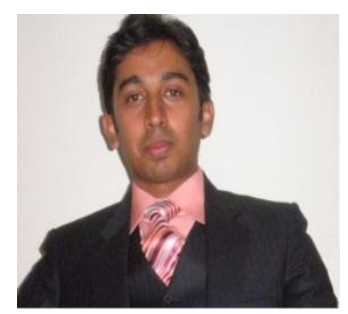

Engr. Ali Javed: serving as an Assistant Professor in Department of Software Engineering, University of Engineering and Technology, Taxila. $\mathrm{He}$ is also $\mathrm{PhD}$ Scholar in the Department of Computer Engineering at University of Engineering and Technology Taxila, Pakistan. He has received his Master degree in Computer engineering from university of Engineering and Technology Taxila, Pakistan in February, 2010. He graduated from University of Engineering and Technology Taxila in Software Engineering in September 2007. His areas of interest are Video Summarization, Digital Image Processing, Computer vision, Software Quality Assurance, Software testing, Software Requirements Analysis and Mobile application development.

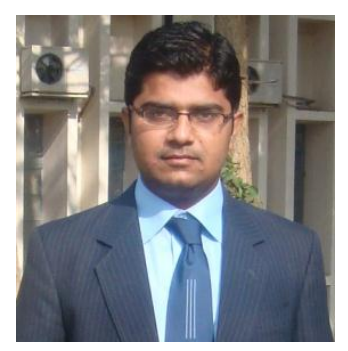

Engr. Mirza Ahsan Ullah: MS Scholar in Department Software Engineering, University of Engineering and Technology Taxila, Pakistan. He has received his bachelor's degree in Computer engineering from university of Engineering and Technology Taxila, Pakistan in August, 2010.Also, he is a professional software developer specialized in ERP systems. His areas of interest are software development, Mobile application development, Data mining, Data bases, Digital image processing, Computer vision and Computer Networks.

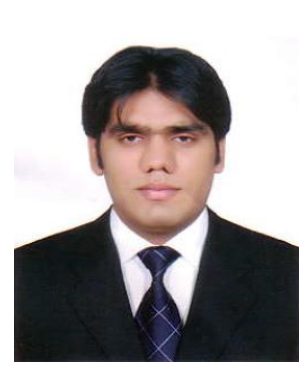

Engr. Aziz Ur Rehman: MS Scholar in Department Software Engineering, University of Engineering and Technology Taxila, Pakistan. He has received his bachelor's degree in electrical engineering with specialize in Telecom from Comsat institute of Information Technology Lahore, Pakistan in July, 2010. His areas of interest are Mobile application development, Data bases, Digital image processing and Computer Networks. 